\title{
INCREASING EMOTIONAL INTELLIGENCE AMONG EARLY ADOLESCENTS: MYTHODRAMA GROUP PSYCHOTHERAPY APPROACH
}

Tinatin Tiabashvili, Rusudan Mirtskhulava, Marine Japaridze

Ilia State University, Tbilisi, Georgia

E-mail: tinatin.tiabashvili@iliauni.edu.ge,rusudan.mirtskhulava@iliauni.edu.ge, marine_japaridze@iliauni.edu.ge

\begin{abstract}
Adolescents exhibit a range of behavior difficulties as a result of the many physical, emotional, and social stresses associated with this developmental stage. Conflicts and occasional aggressive outbursts are common in this period, but this behavior becomes problematic when it is persistent. Allan Guggenbühl's Mythodrama group psychotherapy approach of resolving conflict and bullying in a school setting has been proven successful in Europe and in the USA. The aim of the current study was to provide further evaluation of Mythodrama group work to address emotional and behavioral problems with early adolescents. As emotional abilities and dispositions appear to play a crucial role for adjustment and well-being in adolescence period, the present study investigated, using a controlled experimental design, whether it is possible to increase Emotional Intelligence in pupils received Mythodrama group intervention during three months. Sixty three public school pupils aged 10- to 12-years-old ( $M$ of age $=11.06, S D=0.59$ ), identified by school staff as displaying emotional and behavioral difficulties, were administered with Trait Emotional Intelligence Questionnaire (TEIQue) - Child's form (Petrides, 2008) twice, prior and post Mythodrama group intervention. Repeated measures ANOVA revealed a statistically significant change in seven domains of emotional intelligence, while no significant changes were observed in the control group, except three of the domains. These findings suggest that Emotional Intelligence can be improved using Mythodrama group intervention, but more follow-up research is required to reveal the persistence of the result and its influence on school performance.
\end{abstract}

Key words: emotional intelligence, early adolescents, group psychotherapy, Mythodrama.

\section{Introduction}

Adolescence period, which is often defined as a transition between childhood and adulthood, is marked by physical, cognitive, socio-emotional and interpersonal changes influenced by outside factors, such as environment, culture, religion, school. In this developmental stage youths tend to show a wide range of behavioral difficulties as a result of stressful situations. In recent times an increasing number of adolescents are reported to have emotional and behavioral problems (Achenbach, Dumenci, \& Rescorla, 2002).

Early adolescent emotional and behavioral problems can be classified into two dimensions: internalizing and externalizing groups of problems. Internalizing problems refer to overcontrolled behaviors, which include symptoms related to depression, anxiety, social withdrawal and somatic complaints, while externalizing problems refer to under controlled and overt behaviors including aggression, acting out tendencies, disruptive, defiant, and hyperactive behaviors (Merrell, 2003). In recent times an increasing number of adolescents are reported to have emotional and behavioral problems (Achenbach, Dumenci, \& Rescorla, 2002). As long 
Tinatin TIABASHVILI, Rusudan MIRTSKHULAVA, Marine JAPARIDZE. Increasing emotional intelligence among early adolescents: Mythodrama group psychotherapy approach

OF EDU

PROBLEMS

IN THE $21^{\text {st }}$ CENTURY

Volume 66, 2015

as emotional and behavioral problems remain unidentified or untreated, these may have a long lasting impact on various domains of functioning of the child's life (Suveg, Zeman, FlannerySchroeder, \& Cassano, 2005) ranging from poor school performance, sense of rejection, unemployment and psychiatric problems in later years (e.g., Hughes, Lourea-Waddell, \& Kendall, 2008; Mash \& Wolfe, 2005; Nock \& Kazdin, 2002; Turner, Finkelhor, \& Ormrod, 2010). There is evidence that behavioral problems are for many children relatively stable over time (Bilancia \& Rescorla, 2010; Slemming et al., 2010) though strategic interventions can reduce these challenges (Morrison and Braton, 2010).

Researches evidence a bold link between emotional intelligence and behavioral problems in adolescence period. Cognitive abilities no more considered the only predictor of successful adaptation, but emotional competencies should be taken into consideration.

The concept of Emotional Intelligence (EI) stems from Thorndike's (1920) concept of "social intelligence" to refer to the ability to understand and manage people and to act wisely in human relations. The recent roots of the concept lie in Gardner's theory of multiple intelligences, especially in his concepts of intrapersonal and interpersonal intelligence. Since there are different approaches to Emotional Intelligence, Petrides and Furnham (e.g. Petrides \& Furnham, 2000, 2001) proposed a distinction between two emotional intelligence constructs: trait EI (or trait emotional self-efficacy) and ability EI (or cognitive-emotional ability). This differentiation is based on the type of measurement used in the operationalization process. The first one, Trait EI, which concerns behavioral dispositions and self-perceived abilities, is measured through self-report, whereas ability EI refers to actual emotion-related abilities and must be measured through maximum-performance tests. Trait EI and ability EI are two different constructs conceptually, methodologically and empirically. In this study, we adopted the concept of Trait emotional intelligence, which is defined as a constellation of emotion-related self-perceptions and dispositions at the lower levels of personality hierarchies (Petrides \& Furnham, 2001). Trait Emotional Intelligence or Trait EI self-efficacy provides a comprehensive coverage of emotionrelated personality facets.

According to researches, adolescents with higher trait emotional intelligence and stronger social skills are less likely to present emotional and behavioural difficulties (Maria S. Poulou, 2014). The evidence corroborates an important role for trait emotional intelligence in peer relations and socio-emotional competence in a childhood period (see Frederickson, Petrides, Simmonds, 2012, Mavroveli et al., 2011). Moreover, as researchers point out, trait EI profiling can help to identify children who are more likely to benefit from social and self-esteem interventions in school settings. Early intervention programs targeting such children could produce concrete behavioral modifications as well as improved integration into school systems (Mavroveli et al., 2009).

The therapeutic group work Mythodrama, or as often it is described the "tales, fiction and horror technique" was developed during the last couple of years by Dr. Allan Guggenbühl. The background theory of this group approach is rooted in analytical psychology. Mythodrama group approach is a possible crisis intervention technique for children and juveniles with behavioral and emotional problems. Mythodrama psychotherapy group approach is widely used in Europe, especially in Switzerland as well as the United States in terms of the Seven Step Mythodramatic Intervention Program. This program of resolving conflict and bullying in a school setting has proven to be successful in Europe (Guggenbühl A. et al., 2006) and in US schools (Al-Sammaray, 2011). Recently, Mythodrama has been implemented in Georgia too. The Psychologists have been trained in the method, who work with children and adolescents in the public schools under the supervision of the author of the method.

The aim of the current study was to provide further exploration of the efficacy of an intervention based on A.Guggenbuhl's Mythodrama group approach with young adolescents. More specifically, the study aimed to address the following research questions: Is a Mytho- 
Tinatin TIABASHVILI, Rusudan MIRTSKHULAVA, Marine JAPARIDZE. Increasing emotional intelligence among early adolescents: Mythodrama group psychotherapy approach

drama group intervention effective in improving trait EI in early adolescents, who engage in

emotional and behavioral difficulties?

\section{Methodology of Research}

The quantitative study has been designed to explore the relation between Mythodrama intervention and emotional intelligence on a public school pupil sample. The main hypothesis was as follows: trait EI could be improved among early adolescents after receiving Mythodrama group psychotherapy intervention. Mixed model group (intervention vs. control) repeated measures analysis of variances was performed to indicate a differential change for the two groups.

\section{Participants}

The sample consisted of 63 participants, 40 in the Mythodrama groups, 23 in the controlled group. There were $50 \%$ of male and female in Mythodrama group and $47.83 \%$ female and $52.17 \%$ male in the control group. All participants were public school (Tbilisi, Georgia) 10-12 year old adolescents. The participants for both groups were selected based on emotional and behavioral problems reported by the teachers and parents.

\section{Measurements and Procedure}

The effectiveness of the Mythodrama intervention (Guggenbühl A. et al., 2006) was assessed by the Georgian version of Trait Emotional Intelligence Questionnaire-Child Form (TEIQue-CF). The Child Form is based on a sampling domain that has been specifically developed for children aged between 8 and 12 years. It comprises 75 items responded to on a 5 -point scale ( 1 completely disagree and 5 completely agree) and measures nine distinct facets (Mavroveli, Petrides, Shove, \& Whitehead, 2008) (see Table 1). The participants of Mythodrama groups completed the measures two times: prior to Mythodrama circle and at the end of the circle. One Mythodrama circle consisted of 12-15 sessions of two and half hours, one session per week. In each group participated 10 pupils. Mythodrama sessions were conducted by the interventionists in a larger room in the school building. The teachers were not present. The participants of the control groups completed the same measures as the training group, but were not attending the Mythodrama sessions. 
Tinatin TIABASHVILI, Rusudan MIRTSKHULAVA, Marine JAPARIDZE. Increasing emotional intelligence among early adolescents: Mythodrama group psychotherapy approach

OF EDUCAT

IN THE $21^{\text {st }}$ CENTURY Volume 66, 2015

Table 1. The Sampling Domain of Trait Emotional Intelligence in children (Mavroveli, S.,Petrides, K. V., Shove, C., \& Whitehead, 2008).

\begin{tabular}{lll}
\hline \multicolumn{1}{c}{ Facets } & \multicolumn{1}{c}{ Short descriptions of facets } & \multicolumn{1}{c}{ Example items } \\
\hline Adaptability & $\begin{array}{l}\text { Concerns children's self-perceptions of how well } \\
\text { they adapt to new situations and people }\end{array}$ & $\begin{array}{l}\text { I find it hard to get used to a new } \\
\text { school year }\end{array}$ \\
\hline Affective disposition & $\begin{array}{l}\text { Concerns children's self-perceptions of the } \\
\text { frequency and intensity with which they experience } \\
\text { emotions }\end{array}$ & I'm a very happy kid \\
\hline Emotion expression & $\begin{array}{l}\text { Concerns children's self-perceptions of how effec- } \\
\text { tively they can express their emotions }\end{array}$ & $\begin{array}{l}\text { I always find the words to show how } \\
\text { I feel }\end{array}$ \\
\hline Emotion perception & $\begin{array}{l}\text { Concerns children's self-perceptions of how accu- } \\
\text { rately they identify their own and others emotions }\end{array}$ & $\begin{array}{l}\text { It's easy for me to understand how } \\
\text { I feel }\end{array}$ \\
\hline Emotion regulation & $\begin{array}{l}\text { Concerns children's self-perceptions of how well } \\
\text { they can control their emotions }\end{array}$ & I can control my anger \\
\hline Low impulsivity & $\begin{array}{l}\text { Concerns children's self-perceptions of how effec- } \\
\text { tively they can control their emotions }\end{array}$ & I do not like waiting to get what I want \\
\hline Peer relations & $\begin{array}{l}\text { Concerns children's self-perceptions of the quality of } \\
\text { their relationships with their classmates }\end{array}$ & I listen to other children's problems \\
\hline & $\begin{array}{l}\text { Concerns children's self-perceptions of their self } \\
\text { worth }\end{array}$ & $\begin{array}{l}\text { I feel great about myself } \\
\text { and motivation }\end{array}$ \\
\hline
\end{tabular}

\section{Results of Research}

An independent-sample t-test was conducted to compare the variable scores for both the training and the control group. Table 1 showed that there were no baseline differences between the training and the control group with the exception of Adaptability and Emotion Expression for which scores in the Mythodrama group were higher.

One way repeated measures analyses (ANOVA) revealed a significant difference over time for scores on most TEIQue-CF facets in Mythodrama group, namely: Adaptation Wilks'lamda $=0.706, \mathrm{~F}(1.39)=16.20, \mathrm{p}=.00, \eta \mathrm{p} 2=.294$; Emotion Expression Wilks'lamda $=0.597, \mathrm{~F}(1.39)=26.37, \mathrm{p}=.00, \eta \mathrm{p} 2=.403$; Emotion Perception Wilks'lamda $=0.563$, $\mathrm{F}(1.39)=30.23, \mathrm{p}=.00, \eta \mathrm{p} 2=.437$; Self Esteem Wilks'lamda $=0.641, \mathrm{~F}(1.39)=21.80, \mathrm{p}=.00$, $\eta \mathrm{p} 2=.359$; Low Impulsivity Wilks'lamda $=0.757, \mathrm{~F}(1.39)=12.48, \mathrm{p}=.001, \eta \mathrm{p} 2=.243$; Peer Relations Wilks'lamda $=0.581, \mathrm{~F}(1.39)=28.09, \mathrm{p}=.00, \eta \mathrm{p} 2=.419$; Affective Disposition Wilks'lamda $=0.674, \mathrm{~F}(1.39)=18.82, \mathrm{p}=.00, \eta \mathrm{p} 2=.326$; no significant changes were found for Emotion Regulation Wilks'lamda $=0.994, \mathrm{~F}(1.39)=.221, \mathrm{p}=.641$, $\eta \mathrm{p} 2=.006$; and Self-Motivation Wilks'lamda $=0.920, \mathrm{~F}(1.39)=3.40, \mathrm{p}=.00, \eta \mathrm{p} 2=.080$. Significant changes were not found in a control group, except Adaptability Wilks'lamda $=0.592, \mathrm{~F}(1.22)=15.16, \mathrm{p}=.001, \eta \mathrm{p} 2=.408$; Emotion Expression Wilks'lamda $=0.337, \mathrm{~F}(1.22)=43.32, \mathrm{p}=.00, \eta \mathrm{p} 2=.663$; and Self Esteem Wilks'lamda $=0.673, \mathrm{~F}(1.22)=10.68, \mathrm{p}=.004, \eta \mathrm{p} 2=.327$; (for descriptive statistics see Table 2 ). 
Tinatin TIABASHVILI, Rusudan MIRTSKHULAVA, Marine JAPARIDZE. Increasing emotional intelligence among early adolescents: Mythodrama group psychotherapy approach

Table 2. Means, standard deviations, and significance of differences between time 1 and time 2 for each variable and each group.

\begin{tabular}{lcccccccc}
\hline & \multicolumn{3}{c}{ Intervention Group $(\mathrm{n}=40)$} & \multicolumn{5}{c}{ Control Group (n=23) } \\
\cline { 2 - 9 } & Time 1 & Time 2 & & \multicolumn{7}{c}{ Time 1 } & Time 2 \\
\hline Variable & $\mathbf{M}(\mathrm{SD})$ & $\mathbf{M}(\mathrm{SD})$ & $\mathbf{F}(1.39)$ & $\mathbf{p}$ & $\mathbf{M}(\mathrm{SD})$ & $\mathbf{M}(\mathrm{SD})$ & $\mathbf{F}(1.22)$ & $\mathbf{p}$ \\
\hline Adaptability & $3.47(0.74)$ & $3.79(0.48)$ & 16.20 & .00 & $2.97(0.56)$ & $3.20(0.59)$ & 15.16 & .001 \\
\hline Emotion Expression & $3.30(0.49)$ & $3.57(0.60)$ & 26.37 & .00 & $2.60(0.36)$ & $2.91(0.30)$ & 43.20 & .00 \\
\hline Emotion Perception & $3.52(0.58)$ & $3.98(0.52)$ & 30.23 & .00 & $3.48(0.50)$ & $3.67(0.60)$ & 2.75 & .111 \\
\hline Self Motivation & $3.90(0.58)$ & $4.05(0.50)$ & 3.40 & 0.72 & $3.74(0.74)$ & $3.91(0.55)$ & 1.09 & .308 \\
\hline Self Esteem & $3.29(0.67)$ & $3.72(0.53)$ & 21.80 & 0.00 & $3.32(0.76)$ & $3.56(0.76)$ & 10.68 & .00 \\
\hline Low Impulsivity & $2.79(0.67)$ & $3.10(0.69)$ & 12.48 & 0.001 & $2.81(0.53)$ & $2.97(0.51)$ & 3.29 & .08 \\
\hline Peer Relations & $3.81(0.62)$ & $4.15(0.42)$ & 28.09 & 0.00 & $3.57(0.49)$ & $3.80(0.59)$ & 3.40 & .07 \\
\hline Emotion Regulation & $3.43(0.49)$ & $3.40(0.40)$ & .221 & .641 & $3.41(0.50)$ & $3.54(0.42)$ & 4.14 & .06 \\
\hline Affective Disposi- & $3.29(0.73)$ & $3.77(0.54)$ & 18.82 & .00 & $3.31(0.70)$ & $3.42(0.54)$ & 1.46 & .23 \\
tion & & & & & & & & \\
\hline
\end{tabular}

Mixed-Model Group (training vs. control)_ Time (Time 1 vs. Time 2) repeated measures analyses of variance (ANOVAs) were performed on each facet of TELQue-CF, with the group as the between-subjects factor and time as the within-subject factor. Analyses yielded a significant Group and Time interaction for Emotion Perception Wilks'lambda $=0.932, \mathrm{~F}(1.61)=4.471$, $\mathrm{p}=.039, \eta \mathrm{p} 2=.068$ and for Affective Disposition Wilks'lambda $=0.924, \mathrm{~F}(1.61)=5.002, \mathrm{p}=.029$, $\eta \mathrm{p} 2=.076$.

\section{Discussion}

The purpose of this study was to investigate, whether Emotional Intelligence could be increased in early adolescents reporting as emotional and behavioral problems after receiving Mythodrama intervention. This study is the first attempt to assess whether EI can be optimized using Mythodrama intervention. The major finding of the study is that the intervention group (but not the control group) scored significantly higher on trait emotional intelligence facets (TEIQue) after the intervention. Compared to the control group Mythodrama group showed significant differences in several competencies (emotion perception, affective disposition, low impulsivity, peer relations).

It seems noteworthy that emotion regulation (controlling emotions) was not improved right after the intervention. One possible explanation is that Mythodrama group psychotherapy approach is not oriented specifically on training emotional skills and providing theoretical knowledge of emotion related competencies. Mythodrama relates participants to a story, legend, myth or real event, which are carefully selected by group therapists, according to the problem, challenge or difficulty the group is facing (Guggenbühl, 1999). Stories evoke emotions that are expressed and discussed during sessions in the whole group via drama performance or drawing. Mythodrama functions as a container, since during the sessions the pupils have to confront their feelings, conflicts, anger, fears. The change of emotion regulation facet was not evident on short-term, however, this should be investigated on long- term in order to draw firm conclusions. 
Tinatin TIABASHVILI, Rusudan MIRTSKHULAVA, Marine JAPARIDZE. Increasing emotional intelligence among early adolescents: Mythodrama group psychotherapy approach

OF EDUC

PROBLEMS

IN THE $21^{\text {st }}$ CENTURY

Volume 66, 2015

Peer difficulties in childhood, such as peer rejection, aggression and withdrawal, can have damaging consequences for later personal adjustment (Parker \& Asher, 1987; Pellegrini \& Blatchford, 2000). Low trait emotional self-efficacy may be a key risk factor, alienating children from their peers and leading to antisocial behavior and delinquency later on in life (Petrides, Frederickson, \& Furnham, 2004). Since the previous research evidence the positive influence of Mythodrama in group cohesion, bullying and aggression (Guggenbühl, et al., 2006), it was expected that the trait EI facets responding the understanding of own and others emotions such as emotion perception and peer relations would be increased. The result is in accordance with the previous researches indicating the negative association between bulling and trait EI (e.g. Petrides et al. 2004; Mavroveli and Sánchez-Ruiz 2011; Mavroveli et al. 2009) as well as aggressive and disruptive behavior (Petrides et al. 2006). Researches indicate that children who perceive themselves as emotionally adept are more desirable as friends than children who perceive themselves as emotionally cold and withdrawn. (Petrides et al. 2006).

The results of the presented study corroborate those of several studies, addressing the question of optimizing trait emotional intelligence, following carefully developed intervention programmes (see also Nelis, Quoidbach, Mikolajczak, \& Hansenne, 2009; Ruttledge \& Petrides, 2011). However, most of the studies refer to late adolescence and an adult period of life. In this view, the findings of the current study are particularly breaking a new ground, but future research is called for to explore further correlations with emotional and behavioral problems.

The current research findings have important theoretical and practical implications. At the theoretical level, our results suggest that Mythodrama group work is an effective type of intervention in optimizing trait emotional inlelligence in early adolescents. It opens up a new application of Mythodrama group psychotherapy approach. At the practical level, the results of the study are noteworthy, because trait emotional intelligence is the predictor of numerous positive outcomes such as health, social relationships, school performance, psychological well being (Petrides, Frederickson, \& Furnham, 2004).

\section{Conclusions}

The present study results show that Mythodrama is an effective intervention in optimizing participant trait emotional intelligence (trait EI). The research findings indicated that compared with the control group, intervention group shows a significant improvement in trait EI facets, namely Emotion Perception, Affective Disposition, Low Impulsivity and Peer Relations directly after the intervention.

While the results of this study are encouraging, a number of limitations have been identified regarding the methodologies used in the research design. First, in order to draw firm conclusions about the positive and long term effects of the intervention, the results would have to be compared to a six month follow up results. Second, the relatively small sample size makes it difficult to generalize the findings to other adolescents and to answer the questions such as, whether the intervention outcomes are the same for boys and girls. Third, the follow up data from parents and teachers were collected in many cases anecdotal, quantitative measures would have to be done to find the firm associations between trait EI and emotional and behavioral difficulties as an effect of Mythodrama intervention. 


\section{References}

Achenbach, T. M., Dumenci, L., \& Rescorla, L. A. (2002). Ten-year comparisons of problems and competencies for national sample of youth: Self, parent, and teacher reports. Journal of Emotional and Behavioral Disorders, 10, 194-203.

Agnoli, S., Mancini, G., Pozzoli, T., Baldaro, B., Russo, P. M., \& Surcielli, P. (2012). The interaction between emotional intelligence and cognitive ability in predicting scholar performance school-aged children. Personality and Individual Differences, 53 (5), 660-665.

Babalis, T., Tsoli, K., Artikis, C. T., Mylonakou-Keke, I., \& Xanthakou, Y. (2013). The Impact of Social and Emotional Learning Programs on the Emotional Competence and Academic Achievement of Children in Greek Primary School. World Journal of Education, 3 (6), 54-63.

Bilancia, S. D., \& Rescorla, L. (2010). Stability of behavioral and emotional problems over 6 years in children ages 4 to 5 or 6 to 7 at time 1. Journal of Emotional and Behavioral Disorders, 18 (3), 149-161.

Guggenbühl, A. (1999). Das Mythodrama [The Mythodrama]. Edition IKM, Zürich.

Guggenbühl, A., (2008). Education and imagination: Post-Jungian perspectives. Chapter 5. Taylor \& Francis.

Guggenbühl, A., Hersberger, K., Rom, T., \& Boström, P. (2006). Helping schools in crisis. A scientific evaluation of the Mythodramaic intervention approach in Swiss and Swedish schools. Zürich: IKM Guggenbühl AG.

Hansenne, M., \& Legrand, J. (2012). Creativity, emotional intelligence, and school performance in children. International Journal of Educational Research, 53, 264-268.

Hughes, A. A., Lourea-Waddell, B., \& Kendall, P. C. (2008). Somatic complaints in children with anxiety disorders and their unique prediction of poorer academic performance. Child Psychiatry and Human Development, 39, 211-220.

Kenneth, W. Merrell (2003). Behavioral, Social, and Emotional Assessment of Children and Adolescents. Routledge.

Poulou, M. S. (2014). How are trait emotional intelligence and social skills related to emotional and behavioural difficulties in adolescents? Educational Psychology: An International Journal of Experimental Educational Psychology, 34 (3), 354-366.

Mash, E. J., \& Wolfe, D. A. (2005). Abnormal child psychology (3rd ed.). USA: Wadsworth, Inc.

Mavroveli, S., Sánchez-Ruiz, M. J. (2011). Trait emotional intelligence influences on academic achievement and school behaviour. British Journal of Educational Psychology, 81, 112-134.

Mavroveli, S., Petrides, K. V., Sangareau, Y., \& Furnham, A. (2009). Exploring the relationship between trait emotional intelligence and objective socio-emotional outcomes in childhood. British Journal of Educational Psychology, 79, 259-272.

Mavroveli, S., Petrides, K. V., Shove, C., \& Whitehead, A. (2008). Investigation of the construct of trait emotional intelligence in children. European Child \& Adolescent Psychiatry, 17, 516-526.

Mavroveli, S., Petrides, K. V., Rieffe, C., \& Bakker, F. (2007). Trait emotional intelligence, psychological well-being, and peer-rated social competence in adolescence. British Journal of Developmental Psychology, 25, 263-275.

Merrell, K. W. (2003). Behavioral, social, and emotional assessment of children and adolescents. London: Lawrence Erlbaum Associates, Publishers.

Morrison, B., Mary, O., Bratton, S. C. (2011). The effects of child teacher relationship training on the children of focus: A pilot study. International Journal of Play Therapy, 20 (4), 193-207.

Nelis, D., Quoidbach, J., Mikolajczak, M., Hansenne, M. (2009). Increasing emotional intelligence: (How) is it possible? Personality and Individual Differences, 47, 36-41.

Frederickson, N., Petrides, K. V., Simmonds, E. (2012). Trait emotional intelligence as a predictor of socioemotional outcomes in early adolescence. Personality and Individual Differences, 52, 323 328 .

Nock, M. K., \& Kazdin, A. E. (2002). Examination of affective, cognitive, and behavioral factors and suicide-related outcomes in children and young adolescents. Journal of Clinical Child and Adolescent Psychology, 31 (1), 48-58.

Parker, J. G., \& Asher, S. R. (1987). Peer relations and later personal adjustment: Are low accepted children at risk? Psychological Bulletin, 102, 357-389. 
Tinatin TIABASHVILI, Rusudan MIRTSKHULAVA, Marine JAPARIDZE. Increasing emotional intelligence among early adolescents: Mythodrama group psychotherapy approach

PROBLEMS

OF EDUCATION

IN THE $21^{\text {st }}$ CENTURY

Volume 66, 2015

Pellegrini, A. D., \& Blatchford, P. (2000). The child at school: Interactions with peers and teachers. London: Arnold.

Petrides, K. V., \& Furnham, A. (2000). On the dimensional structure of emotional intelligence. Personality and Individual Differences, 29, 313-320.

Petrides, K. V., \& Furnham, A. (2001). Trait emotional intelligence: Psychometric investigation with reference to established trait taxonomies. European Journal of Personality, 15, 425-448.

Petrides, K. V., Sangareau, Y., Furnham, A., \& Frederickson, N. (2006). Trait emotional intelligence and children's peer relations at school. Social Development, 15, 537-547.

Petrides, K. V., Frederickson, N., \& Furnham, A. (2004). The role of trait emotional intelligence in academic performance and deviant behavior at school. Personality and Individual Differences, 36, 277-293.

Ruttledge, R. A., Petrides, K. V. (2011). A cognitive behavioural group approach for adolescents with disruptive behavior in schools. School Psychology International, 33 (2) 223-239.

Slemming, K., Sorensen, M. J., Thomsen, P. H., Obel. C., Henriksen, T. B., \& Linnet, K. M. (2010). The association between preschool behavioral problems and internalizing difficulties at age 10-12 years. European Child and Adolescents Psychiatry, 19, 787-795.

Suveg, C., Zeman, J., Flannery-Schroeder, E., \& Cassano, M. (2005). Emotion socialization in families of children with an anxiety disorder. Journal of Abnormal Child Psychology, 33 (2), 145-155.

Turner, H. A., Finkelhor, D., \& Ormrod, R. (2010). Child mental health problems as risk factors for victimization. Child Maltreatment, 15 (2), 132-143.

Advised by Natela Imedadze, Ilia State University, Tbilisi, Georgia

Received: June 04, 2015

Accepted: July 28, 2015

Tinatin Tiabashvili

Ph.D. Student, llia State University, Kakutsa Cholokashvili ave. 3/5, 0162

Tbilisi, Georgia.

E-mail: tinatin.tiabashvili@iliauni.edu.ge

Rusudan Mirtskhulava Ph.D., Professor, llia State University, Kakutsa Cholokashvili ave. 3/5, 0162

Tbilisi, Georgia.

E-mail: rusudan.mirtskhulava@iliauni.edu.ge

Marine Japaridze

Ph.D., Professor, llia State University, Kakutsa Cholokashvili ave. 3/5, 0162

Tbilisi, Georgia.

E-mail: marine_japaridze@iliauni.edu.ge 